\title{
The numerical analysis of the long-term behaviour of the reinforced concrete beams strengthened with carbon fiber reinforced polymer: Deflection
}

\author{
Mykolas Daugevičius $^{1}$, Juozas Valivonis ${ }^{2}$, Tomas Skuturna ${ }^{3}$ \\ Department of Reinforced Concrete Structures and Geotechnics, \\ Vilnius Gediminas Technical University, Vilnius, Lithuania \\ E-mail: ${ }^{1}$ mykolas.daugevicius@vgtu.lt (corresponding author)
}

\begin{abstract}
The numerical analysis of the reinforced concrete beams strengthened with CFRP is presented. The beams previously tested experimentally under long-term loading are selected for numerical simulation. The numerical modelling is performed by evaluating the beam's work at various stages: the work stage before the long-term loading period, the work stage under the long-term load action, the work stage when the external load is removed and the work stage until failure. The work stages of all modelled beams are described in more detail. To analyse the behaviour of beams at different work stages, the numerical modelling using the phase analysis is performed. Different finite element groups are evaluated in each phase of analysis. The external load is increased, maintained and reduced. The finite elements of the CFRP layer are activated at a certain work stage for evaluating the strengthening effect. To assess the accuracy of the numerical analysis, each beam is modelled from the finite elements of various sizes. The paper presents the process of the numerical modelling and the predicted deflections. The numerically predicted deflections are compared with the deflections of the experimental study. The modelling of the behaviour of the strengthened beams has shown that the nature of the long-term deflection differs from that obtained in the experiment. The increment of the numerically predicted deflection decreases gradually over the long-term period. Meanwhile, the experimental long-term deflection increment is characterised by the sharp increase and decrease at the start of the long-term period. This contradiction shows that the experimental long-term deflections are greater. However, over time, the numerical model deflections may reach and exceed the experimental deflections due to steady increase. The smaller size of the finite elements causes the increase in the cracking moment and the higher moment when the yielding of the tensioned reinforcement occurs. However, the cracking moment obtained by the numerical modelling is much higher than that obtained by the experimental modelling. However, when the yielding strength of the tensile reinforcement is reached, the considered moment is smaller than the experimental one.
\end{abstract}

Keywords: numerical analysis, long-term loading, deflection.

\section{Introduction}

The distribution of the internal stresses and forces in the RC beam's section changes after its strengthening. The evolution of the internal stresses and forces during a long-term loading period is less investigated. The investigation can be based on the long-term experiment or the numerical analysis. Modern finite element analysis (FEA) programs can evaluate creep and shrinkage. A long-term experiment requires much time and efforts. Besides, a special lab and equipment are required. Therefore, a long-term experiment can be very expensive. The aim of the present work is to investigate the long-term behaviour of the strengthened beams by using the finite element analysis program. The results of the numerical analysis can be compared with the experimentally obtained data (Daugevičius, Valivonis, \& Marčiukaitis, 2012; Daugevičius \& Valivonis, 2013). For performing the numerical analysis the FEA program TNO DIANA (version 9.6) developed by TNO DIANA (the user manual by Jonna Manie and Wijtze Pieter Kikstra) is used. This program is chosen because it is ergonomic and easy to use. The analysis of the behaviour by using the FEA program helps to reduce time, efforts and the experimental resources.

\section{The investigated elements}

The description of the investigated strengthened beams was presented in the previous articles (Daugevičius et al., 2012; Daugevičius \& Valivonis, 2013). Four beams were chosen for the numerical analysis. The names and the view of the beams are presented in Table 1. 

beams strengthened with carbon fiber reinforced polymer: deflection

Table 1. Names and characteristics of the strengthened beams (Daugevičius \& Valivonis, 2013)

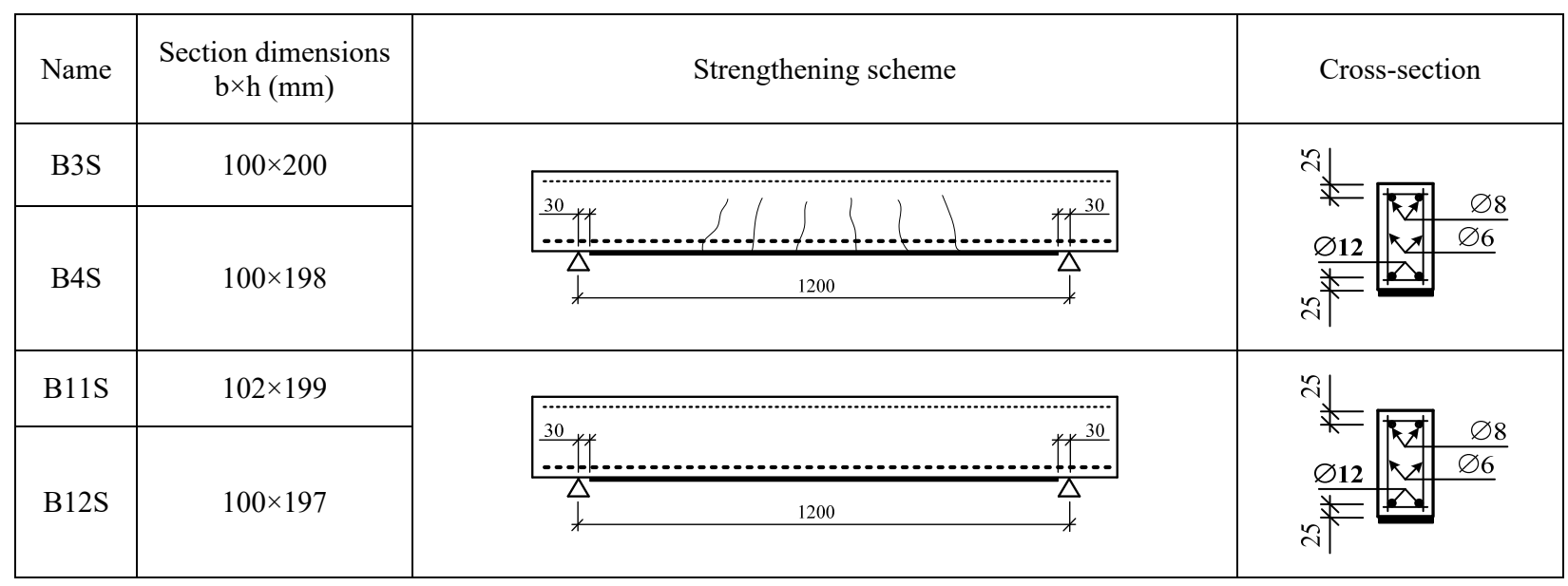

The beams differ in the way they were strengthened and tested. The beams B3S and B4S were strengthened under the external load action. The beams B11S and B12S were strengthened without the external load action. Serviceability of these beams can be described by particular loading stages. For a more thorough analysis and understanding of their behaviour, the loading of the beams and the evolution of deformations were divided into stages. At the first stage, the beams were not cracked and loaded. The deformations were increasing until the first vertical crack appeared, i.e. until the cracking moment $\left(0<\mathrm{M}_{\mathrm{I}} \leq \mathrm{M}_{\mathrm{I} . \mathrm{u}}=\mathrm{M}_{\mathrm{crc}}\right)$ was reached. The second stage continued until the yielding of the reinforcement (the tensioned steel bars) was achieved $\left(\mathrm{M}_{\text {crc }}=\mathrm{M}_{\mathrm{I} . \mathrm{u}}<\mathrm{M}_{\text {II }} \leq \mathrm{M}_{\text {II.u }}=\right.$ $\left.\mathrm{M}_{\mathrm{y}}\right)$. The third stage continued until the failure of the beam $\left(\mathrm{M}_{\mathrm{y}}=\mathrm{M}_{\text {II.u }}<\mathrm{M}_{\text {III }} \leq \mathrm{M}_{\text {III.u }}=\mathrm{M}_{\mathrm{u}}\right)$ took place. The second stage also included substages (Figure 1). The description of the loading stages and the duration of the long-term loading of the considered beams are presented in Tables 2 and 3.

(a)

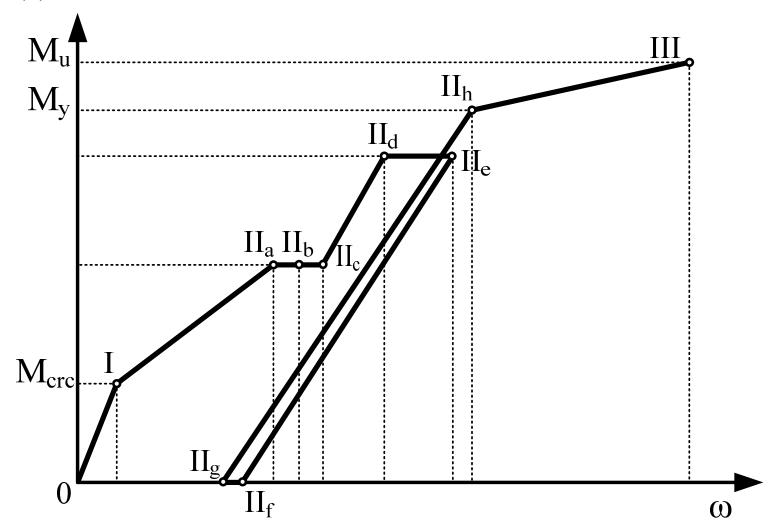

(b)

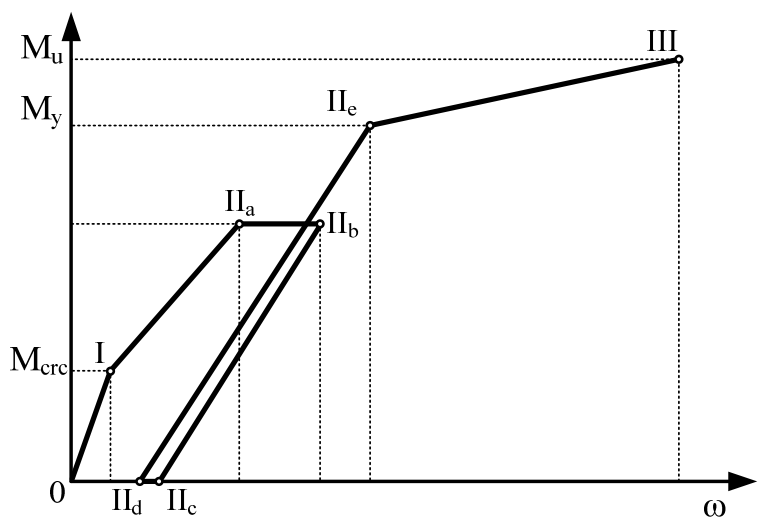

Figure 1. Load deflection history of the investigated beams: a) is the bending moment - deflection stages of the beams B3S and $\mathrm{B} 4 \mathrm{~S} ; \mathrm{b}$ ) is the bending moment - deflection stages of the beams B11S and B12S

Table 2. The loading stages, load levels and the retention time for the beams B3S and B4S

\begin{tabular}{|c|l|c|c|}
\hline Stage & \multicolumn{1}{|c|}{ Description } & Load & Time \\
\hline $0 \ldots . . . . \mathrm{II}_{\mathrm{a}}$ & The RC beam loaded until the long-term load level was reached & $F=0.6 \cdot F_{u}$ & $t_{1}=0$ \\
\hline $\mathrm{II}_{\mathrm{a} . . . \mathrm{II}}$ & The retention of the long-term load and strengthening & $F=0.6 \cdot F_{u}$ & $t_{\text {str }}=14$ \\
\hline $\mathrm{II}_{\mathrm{b} . . . \mathrm{II}_{\mathrm{c}}}$ & The retention of the long-term load after strengthening & $F=0.6 \cdot F_{u}$ & $t_{2}=29$ \\
\hline $\mathrm{II}_{\mathrm{c} . . . \mathrm{II}_{\mathrm{d}}}$ & The external load increased to achieve the new long-term load level & $F=0.98 \cdot F_{u}$ & $t_{3}=29$ \\
\hline $\mathrm{II}_{\mathrm{d} . . . \mathrm{II}}$ & The retention of the long-term load & $F=0.98 \cdot F_{u}$ & $t_{4}=555 ; t_{4-3}=526$ \\
\hline $\mathrm{II}_{\mathrm{e}} \ldots \mathrm{II}_{\mathrm{f}}$ & Unloading & $F=0$ & $t_{5}=555$ \\
\hline $\mathrm{II}_{\mathrm{f} . . . \mathrm{II}_{\mathrm{g}}}$ & The retention of the unloaded beam & $F=0$ & $t_{6}=623 ; t_{6-5}=68$ \\
\hline $\mathrm{II}_{\mathrm{g} . . . . \mathrm{II}_{\mathrm{h}} . . . \mathrm{III}}$ & Loading until failure & $F=F_{\max }$ & \\
\hline
\end{tabular}



beams strengthened with carbon fiber reinforced polymer: deflection

Table 3. The loading stages, load levels and the retention time for the beams B11S and B12S

\begin{tabular}{|c|l|c|c|}
\hline Stage & \multicolumn{1}{|c|}{ Description } & Load & Time \\
\hline $0 \ldots . . . . \mathrm{II}_{\mathrm{a}}$ & $\begin{array}{l}\text { RC strengthened beam loaded until the long-term load level was } \\
\text { reached }\end{array}$ & $F=0.6 \cdot F_{\text {u.str }}$ & $t_{1}=0$ \\
\hline $\mathrm{II}_{\mathrm{a} . . . \mathrm{II}_{\mathrm{b}}}$ & The retention of the long-term load & $F=0.6 \cdot F_{\text {u.str }}$ & $t_{2}=252$ \\
\hline $\mathrm{II}_{\mathrm{b} . . . \mathrm{II}_{\mathrm{c}}}$ & Unloading & $F=0$ & $t_{3}=252$ \\
\hline $\mathrm{II}_{\mathrm{c} . . . \mathrm{II}}$ & The retention of the unloaded beam & $F=0$ & $t_{4}=270 ; t_{4-3}=18$ \\
\hline $\mathrm{II}_{\mathrm{d} . . . . \mathrm{II} \text { e...III }}$ & Loading until failure & $F=F_{\max }$ & \\
\hline
\end{tabular}

\section{The numerical analysis}

The finite element model of the analysed beams was created by using the program "midas FX+", while the nonlinear finite element analysis was performed by using the program "TNO DIANA".

The strengthening manner of the beams required different phases of analysis. The finite element analysis of the beams B3S and B4S was divided into two phases. At the first analysis phase of the beams B3S and B4S, only the reinforced concrete part of the FEA model was loaded until the long-term load level was reached. In the second phase, the CFRP plate elements were introduced. The numerical analysis of the beams B11S and B12S included only one phase. The description of the numerical analysis is presented in Tables 4 and 5. The finite element model of the $\mathrm{RC}$ beam was made from the 3D quadrilateral element. The internal steel reinforcement was evaluated as the embedded reinforcement made of the line elements. The external layer of CFRP was modelled as the 2D face element. The interface between the RC part and the CFRP layer was not assessed. The FEA model of the beams is presented in Figure 2. Due to the symmetrical cross-section, only one half of the beam was analysed.

(a)

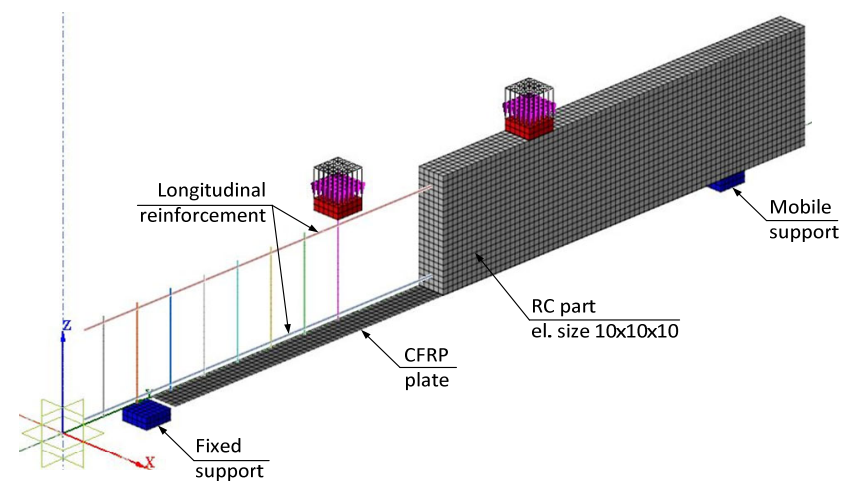

(b)

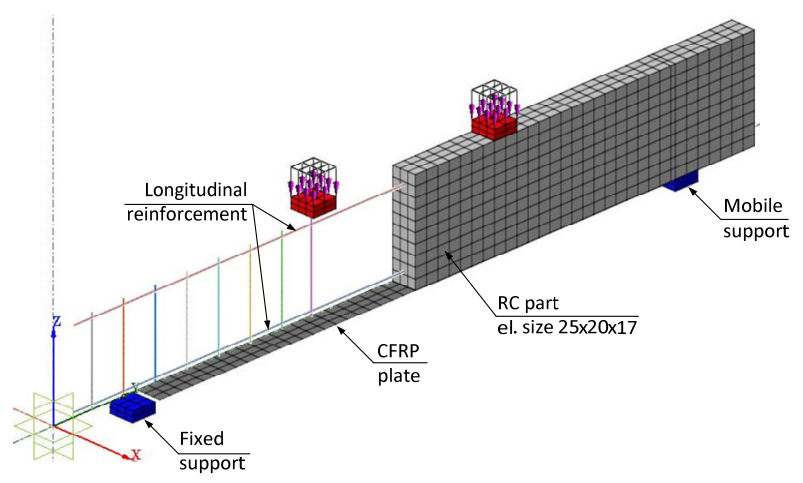

Figure 2. The FEA model of the considered strengthened beams

Table 4. Steps of the numerical analysis of the beams B3S and B4S

\begin{tabular}{|c|c|c|c|c|}
\hline Stage & Phase & The processes taking place in the phase & Elements & Equilibrium iteration \\
\hline $0 \ldots \mathrm{I}_{\mathrm{N}} . . \mathrm{II}_{\mathrm{a}}$ & \multirow{2}{*}{ Phase 1} & Loading, $\mathrm{F}=0.6 \cdot \mathrm{F}_{\mathrm{u}}=35.3 \mathrm{kN}$ & \multirow{2}{*}{$\begin{array}{c}\mathrm{RC} \\
\text { beam }\end{array}$} & \multirow{2}{*}{$\begin{array}{l}\text { Method: secant, max. } 200 \text { iterations. } \\
\text { Convergence norm according to } \\
\text { displacement }\end{array}$} \\
\hline $\mathrm{II}_{\mathrm{a} . . . \mathrm{II}_{\mathrm{b}}}$ & & Load retention, $\mathrm{t}=14$ days & & \\
\hline $\mathrm{II}_{\mathrm{b} . . . . I_{\mathrm{c}}}$ & \multirow{6}{*}{ Phase 2} & $\begin{array}{l}\text { The load of the previous phase was used. } \\
\text { Load retention, } t=15 \text { days }\end{array}$ & \multirow{6}{*}{$\begin{array}{c}\mathrm{RC} \\
\text { beam }+ \\
\text { CFRP }\end{array}$} & \multirow{6}{*}{$\begin{array}{l}\text { Method: secant, max. } 200 \text { iterations. } \\
\text { Convergence norm according to } \\
\text { displacement }\end{array}$} \\
\hline $\mathrm{II}_{\mathrm{c} . . . \mathrm{II}_{\mathrm{d}}}$ & & Increasing the load, $\mathrm{F}=0.98 \cdot \mathrm{F}_{\mathrm{u}}=56.48 \mathrm{kN}$ & & \\
\hline $\mathrm{II}_{\mathrm{d}} \ldots . . \mathrm{II} \mathrm{e}$ & & Load retention, $\mathrm{t}=526$ days & & \\
\hline $\mathrm{II}_{\mathrm{e} . . . . I I f}$ & & Unloading, $\mathrm{F}=0 \mathrm{kN}$ & & \\
\hline $\mathrm{II}_{\mathrm{f} . . . \mathrm{II} g}$ & & Retention, $\mathrm{t}=68$ days & & \\
\hline $\mathrm{IIg}_{\mathrm{g} . . . \mathrm{IIh} . . . \mathrm{III}}$ & & Loading until failure & & \\
\hline
\end{tabular}


Daugevičius, M.; Valivonis, J.; Skuturna, T. 2019. The numerical analysis of the long-term behaviour of the reinforced concrete beams strengthened with carbon fiber reinforced polymer: deflection

Table 5. Steps of the numerical analysis of the beams B11S and B12S

\begin{tabular}{|c|c|c|c|c|}
\hline Stage & Phase & The processes taking place in the phase & Elements & Equilibrium iteration \\
\hline $0 \ldots \mathrm{I}_{\mathrm{I}} \mathrm{II}_{\mathrm{a}}$ & \multirow{5}{*}{ Phase 1} & Loading, $\mathrm{F}=0.6 \mathrm{Fu}=59.96 \mathrm{kN}$ & \multirow{5}{*}{$\begin{array}{l}\text { RC beam } \\
+ \text { CFRP }\end{array}$} & \multirow{5}{*}{$\begin{array}{l}\text { Method: secant, max. } 200 \text { iterations. } \\
\text { Convergence norm according to } \\
\text { displacement }\end{array}$} \\
\hline $\mathrm{II}_{\mathrm{a} \ldots \ldots} \ldots \mathrm{II}_{\mathrm{b}}$ & & Load retention, $\mathrm{t}=252$ days & & \\
\hline $\mathrm{II}_{\mathrm{b} \ldots . . . \mathrm{II}_{\mathrm{c}}}$ & & Unloading, $\mathrm{F}=0 \mathrm{kN}$ & & \\
\hline $\mathrm{II}_{\mathrm{c} . . . . I_{\mathrm{d}}}$ & & Retention, $\mathrm{t}=18$ days & & \\
\hline 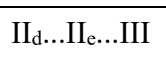 & & Loading until failure & & \\
\hline
\end{tabular}

Concrete creep and shrinkage effect was evaluated according to the CEB-FIP model code 1990, which was implemented in the TNO DIANA analysis procedure (Manie \& Kikstra, 2011). Elasto-plastic work of reinforcement was evaluated according to Von Mises material model and only elastic work was evaluated for the CFRP plate.

\section{The comparative analysis of the obtained experimental and numerical data}

The comparison of the experimental and numerical deflection data is presented in Figures 3 and 4 . The initial numerically predicted deflections of all the investigated beams were smaller compared to the experimentally predicted data. Evaluating the CEB-FIP model code 1990 resulted in this difference. In fact, the overestimated cracking moment increased the difference in the deflection curves. Using the total strain cracking model allows for obtaining the perfect coincidence, however, the version of the program used unfortunately does not perform a long-term analysis using the considered model.

(a)

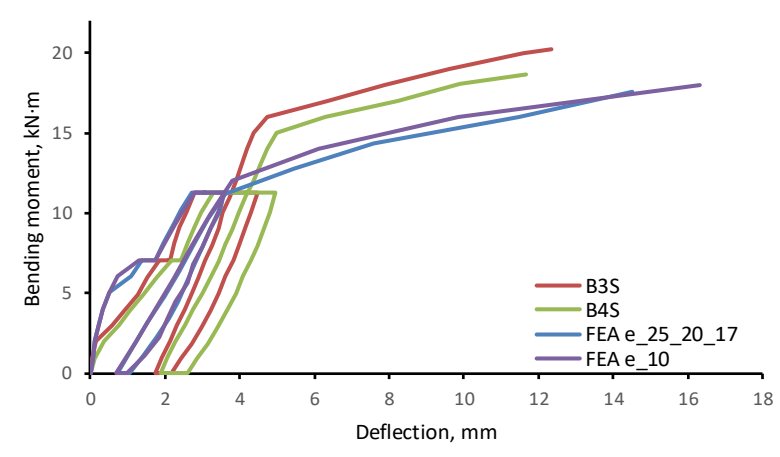

(c)

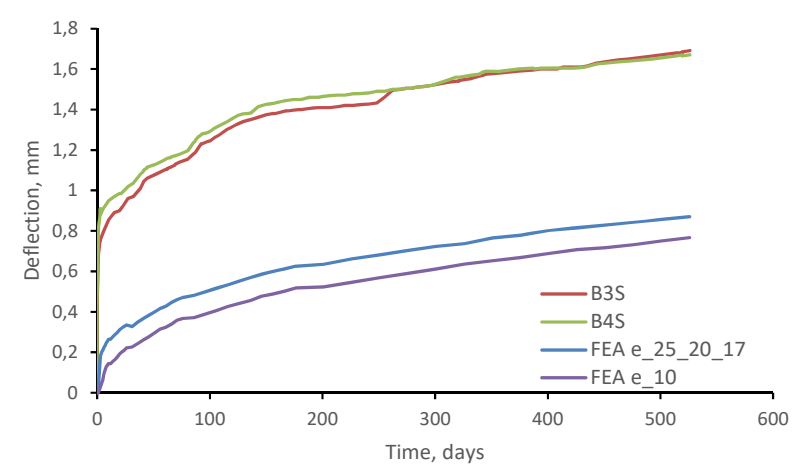

(b)

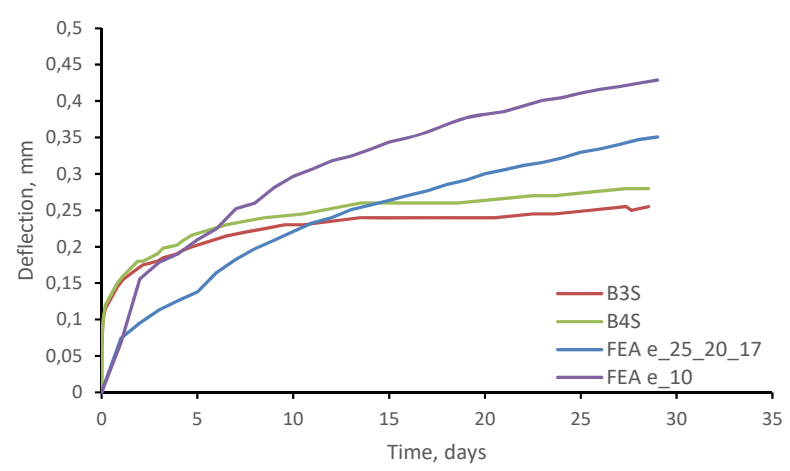

(d)

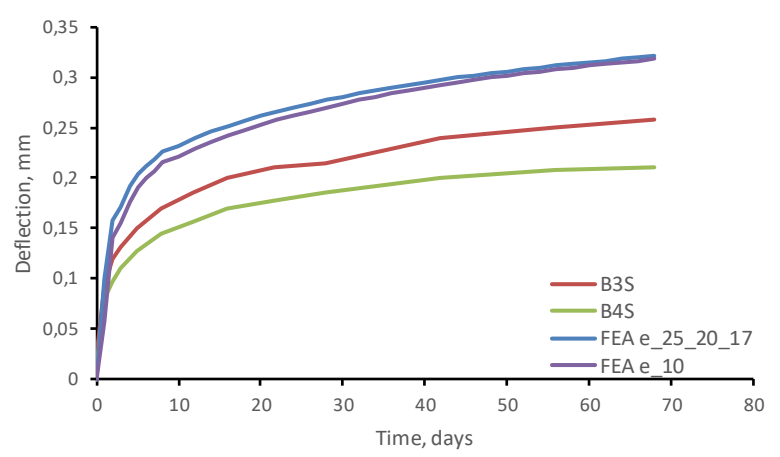

Figure 3. The evolution of deflection of the beams B3S and B4S: a) is the deflection at all stages; b) is the deflection at stage $\mathrm{II}_{\mathrm{a}}-\mathrm{II}_{b}-\mathrm{II}_{\mathrm{c}} ; \mathrm{c}$ ) is the deflection at stage $\mathrm{II}_{\mathrm{d}}-\mathrm{II}_{\mathrm{e}} ; \mathrm{d}$ ) is the deflection at stage $\mathrm{II}_{\mathrm{f}}-\mathrm{II}_{\mathrm{g}}$ 
(a)

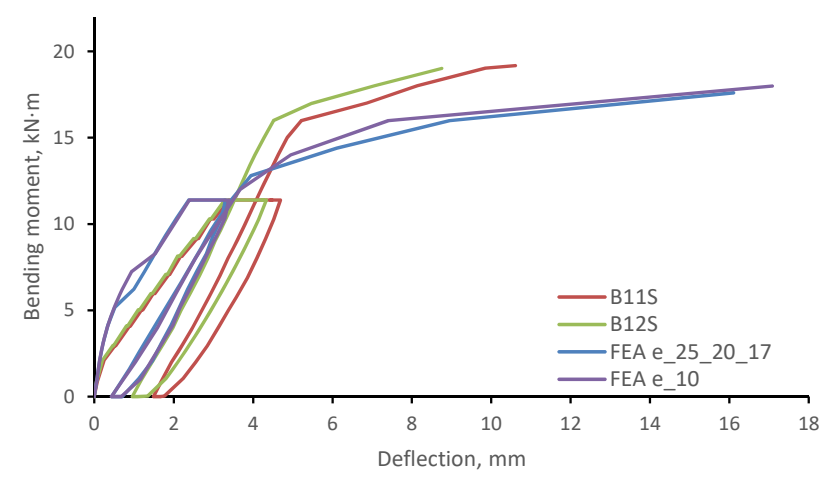

(b)

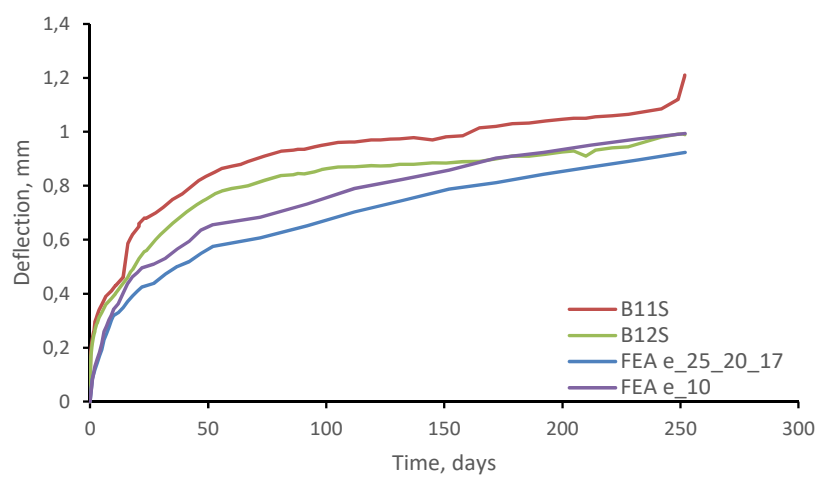

(c)

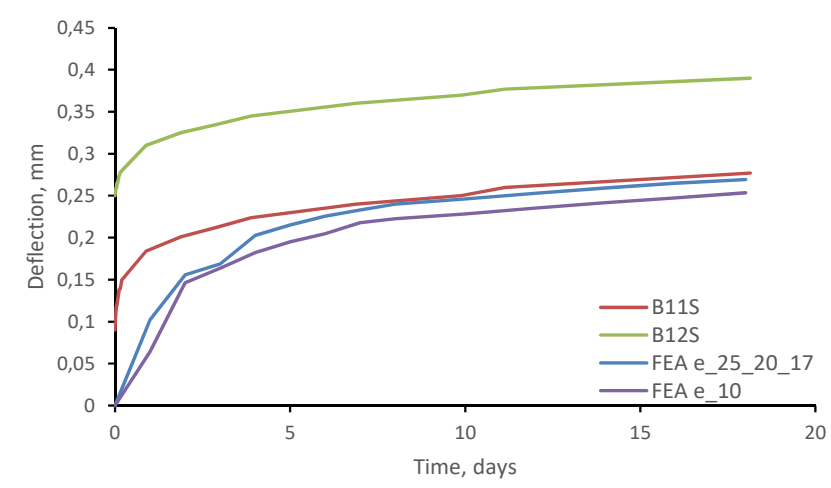

Figure 4. The evolution of the deflection of the beams B11S and B12S: a) is the deflection at all stages; b) is the deflection at stage $\left.\mathrm{II}_{\mathrm{a}}-\mathrm{II}_{\mathrm{b}} ; \mathrm{c}\right)$ is the deflection at stage $\mathrm{II}_{\mathrm{c}}-\mathrm{II}_{\mathrm{d}}$

The numerically predicted long-term deflection increment of the beams B3S and B4S is characterised by a steady increase only for the work stage of the unstrengthened RC beam. Meanwhile, the experimental long-term deflection is characterised by a sudden increase over a short period of time (see Figure 3, b). After strengthening and increasing the external load, the numerically predicted long-term deflection increment retained its steady increment. The experimental increment of deflection demonstrates a large increment in the short period of time (see Figure 3, c). This large experimental increment can be accounted for by the late incorporation of the CFRP layer into the beam's work. The following evolution of the deflection increment is the same because the curves are parallel. The smaller size of the finite element caused the increase in the cracking and the yield moments. The numerically predicted cracking moment was larger than the experimental one, but the yield moment was smaller.

The difference between the numerical and the experimental long-term deflection increments of the beams B11S and B12S (see Figure 4, b) was not so obvious, compared to that for the beams B3S and B4S. The external layer of CFRP was incorporated into the work of beam from the beginning of loading. In that case, the smaller size of the finite element also led to the increase in the cracking and the yield moments. However, the numerically predicted yield moment of the beams B3S and B4S strengthened under the action of the external load was smaller than that of the beams B11S and B12S strengthened before loading.

\section{Conclusions}

The finite element analysis allows for simulating all the stages of the strengthened RC beams' performance. The accuracy of the obtained numerical results depends on the material model used. The numerically predicted cracking moment was greater than the experimental one, while the yield moment was smaller. The numerically predicted increment of the long-term deflection was characterized by a steady growth, while the experimental increment was characterized by a sudden or great growth. This phenomenon should be investigated by choosing smaller time steps in the finite element analysis. 
Daugevičius, M.; Valivonis, J.; Skuturna, T. 2019. The numerical analysis of the long-term behaviour of the reinforced concrete beams strengthened with carbon fiber reinforced polymer: deflection

\section{References}

Daugevičius, M., \& Valivonis, J. (2013, June). Behavior of reinforced concrete beams strengthened with CFRP under long-term load action. In $11^{\text {th }}$ International Symposium on Fiber Reinforced Polymers for Reinforced Concrete Structures (FRPRCS-11). Guimarães, Portugal.

Daugevičius, M., Valivonis, J., \& Marčiukaitis, G. (2012). Deflection analysis of reinforced concrete beams strengthened with carbon fibre reinforced polymer under long-term load action. Journal of Zhejiang University-SCIENCE A (Applied Physics \& Engineering), 13(8), 571-583. https://doi.org/10.1631/jzus.A1100317

Manie, J., \& Kikstra, W. P. (2011). DIANA finite element analysis. User's manual. Analysis procedures. Release 9.4.4 (1 $1^{\text {st }}$ ed.). TNO DIANA BV, Delft, The Netherlands. 